\title{
Short Term Effect of Mixed Tinnitus Retraining Therapy
}

\author{
Sung-Won Chung and Myung-Whan Suh \\ Department of Otorhinolaryngology, Dankook University College of Medicine, Cheonan, Korea
}

\section{혼합형 이명재훈련의 단기 치료 효과}

\author{
정 성 원·서 명 환 \\ 단국대학교 의과대학 이비인후과학교실
}

\author{
Received July 22, 2011 \\ Revised September 14, 2011 \\ Accepted September 20, 2011 \\ Address for correspondence \\ Myung-Whan Suh, MD \\ Department of Otorhinolaryngology, \\ Dankook University College of \\ Medicine, 359 Manghyang-ro, \\ Dongnam-gu, Cheonan 330-715, \\ Korea \\ Tel $+82-41-550-3974$ \\ Fax +82-41-556-1090 \\ E-mail drmung@naver.com
}

Background and Objectives The long-term effect of tinnitus retraining therapy (TRT) is excellent while its short-term effect is known to be inferior to tinnitus making (TM). In this regard, we mixed TRT (mTRT) by combining TRT and TM to improve the short-term effect of TRT. This study evaluated the short-term effect of the mTRT and also compared the clinical efficacy between mTRT and TM.

Subjects and Method Twenty patients who underwent mTRT due to chronic subjective tinnitus were included in this study. Sound therapy of the mTRT was performed with mixed noise of broadband noise and narrow band noise. The broadband noise was used for TRT and the narrow band noise was used for TM. During the first month of mTRT, sound therapy was mainly composed of narrow band noise. During the second month, the proportion of broadband noise was gradually increased to $2 / 3$. After 3 months, only the broadband noise was applied. Tinnitus Handicap Inventory (THI), Visual Analog Scale (VAS) on annoyance and the tinnitus awareness duration (hr/day) was checked as the outcome measures. The outcome was also compared between mTRT and TM.

Results The THI score decreased significantly from $41.8 \pm 24.3$ to $27.3 \pm 25.6$ after mTRT. The VAS (from $5.9 \pm 1.4$ to $4.7 \pm 1.8$ ) and the tinnitus awareness duration (from $18.5 \pm 8.2$ to $12.6 \pm 10.7)$ also showed a significant improvement after treatment. When the treatment outcome was compared between mTRT and TM, there was no significant difference.

Conclusion mTRT seems to be effective in relieving the discomfort of tinnitus. Similar shortterm outcomes can be expected from mTRT as they did in TM.

Korean J Otorhinolaryngol-Head Neck Surg 2011;54:693-8

Key Words Tinnitus · Tinnitus retraining therapy · Tinnitus masking - Sound therapy.

서 론

이명은 외부의 소리 자극이 없는 상황에서 환자가 자각하는 소리 중 일상생활에 심한 불편을 끼치는 불쾌한 소리를 의미 한다. ${ }^{1)}$ 이명으로 인한 불편함은 일상생활과 사회활동을 포함 한 전반적인 삶의 질에 영향을 미침에도 불구하고, 아직까지 이명을 완전하게 치료할 수 있는 방법이 없다. 다양한 치료 방 법들 중 음향을 이용한 이명 치료 방법은 크게 이명 차폐 치료 (tinnitus masking, TM)와 이명재훈련 치료(tinnitus retraining therapy, TRT) 두 가지 종류로 구분할 수 있다. TM은 차
폐음을 듣는 동안 환자가 이명을 인지하지 못하게 하여 불쾌 함을 경감시키는 치료 방법이다. ${ }^{2)}$ 이와 달리 TRT는 이명에 대한 습관화를 유도하여 중추 신경계에서 이명의 인지 과정 을 차단하고 이명으로 인한 괴로움을 경감시키는 치료 방법 이다. ${ }^{3)}$ 일반적으로 $\mathrm{TM}$ 은 빠른 시간 내에 효과가 나타나지만 장기 치료 효과가 좋지 못하고, TRT는 장기 치료 효과가 좋 지만 단기 치료 효과가 미진한 것으로 알려져 있다." ${ }^{4)}$ 2006년 Henry 등 ${ }^{5}$ 은 123 명의 이명 환자를 대상으로, 위 두 가지 치 료 방법의 효과를 비교하는 무작위 대조군 연구 결과를 발 표하였다. 18 개월 동안의 치료 성적을 비교한 결과 기존에 알 
려진 바와 같이 6개월 이후부터는 TRT 환자군의 치료 효과 가 TM에 비하여 유의하게 좋았다. 그러나 치료 직후 3 개월까 지는 오히려 $\mathrm{TM}$ 환자군의 성적이 더 좋았다. 즉 $\mathrm{TRT}$ 가 $\mathrm{TM}$ 보다 좋은 효과를 발휘하기 위해서는 3개월 정도의 시간이 소 요된다고 주장하였다.

이명 치료시 궁극적으로는 장기 치료 효과가 중요하지만, 환자의 순응도를 높이고 중도탈락 환자의 비율을 낮추기 위 해서는 단기 치료 효과도 임상적으로 중요하다. 이에 저자들 은 위 두 가지 치료 방법을 적절히 혼합하여, TRT의 장기 치 료 효과를 유지하면서도 TM의 단기 치료 효과를 함께 이용 할 수 없을지 고민하게 되었다. 즉 TRT를 시행하되, 치료 초 기에 TM을 적용하여 단기 치료 효과를 개선하는 방법을 고 안하게 되었다. 기존의 전통적인 TRT와 개념을 구분하기 위해 저자들은 이상과 같은 치료 방법을 mixed TRT(mTRT)라고 명명하였다. mTRT는 전통적인 TRT와 지도 상담을 포함한 대부분 내용이 동일하지만, 치료 초기에 협대역 잡음으로 차 폐를 시도한다는 점이 유일하게 다르다. 이후 1 3개월에 걸 쳐 단계적으로 넓은 주파수 영역의 백색 잡음으로 음향 치료 를 바꾸어 나가게 된다. 본 연구의 목적은 첫째, 저자들이 고 안한 mTRT가 이명을 치료하는 데 효과가 있는지를 검증하 는 것이었다. 둘째, mTRT의 단기 치료 효과가 실제로 $\mathrm{TM}$ 의 단기 치료 효과만큼 우수한지 알아보고자 하였다.

\section{대상 및 방법}

\section{대 상}

1단계: $\mathrm{mTRT}$ 의 이명 치료 효과 규명

mTRT의 이명 치료 효과를 검증하기 위해, 2009년 1월부터 2010년 2월까지 주관적 만성 이명을 주소로 mTRT를 시행한 환자 20 명의 결과를 분석하였다. 환자들의 평균 연령은 50.9 \pm 13.3 세였고, 남녀비는 1.86 : 1이었다. 병측은 왼쪽 귀가 10 명, 오른쪽 귀가 6 명, 양측 귀가 4명이었다. 청력이 정상인 환 자가 5 명, 경도난청 환자가 3 명, 중등도난청이 1 명, 중등고도난 청이 3 명, 고도난청인 환자가 1 명이었다. 환자들의 평균 이명 유병기간은 $65.7 \pm 86.2$ 주였고 평균 추적관찰 기간은 $10.6 \pm$ 4.5주였다. 이명의 심리음향적 평가에서 이명의 소리가 순음 (pure tone)에 가까운 환자가 12명(60\%), 협대역 잡음(narrow band noise)이 6명(30\%), 백색 잡음(white noise)이 2명(10\%) 이었다. 이명의 주파수는 $8 \mathrm{kHz}$ 가 13명(65\%)으로 가장 많았다.

\section{2단계: $\mathrm{mTRT}$ 와 TM의 단기 치료 효과 비교}

2008년 3월부터 12월까지 TM을 시행하였고 추적관찰 기간
이 2개월 이상인 환자 8 명의 치료 성적을 $\mathrm{mTRT}$ 시행 환자군 과 비교하였다. mTRT를 시행한 환자군은 1단계 분석에 포함 되었던 20명 중 추적관찰 기간이 2개월 이상인 13명만을 대 상으로 하였다. 두 환자군의 평균 연령과 성별은 통계적으로 유의한 차이를 보이지 않았고, 이명 유병기간 및 이명의 병측 역시 두 군 간에 차이가 없었다(Table 1). 치료 전 이명의 심리 음향학적 평가 결과 mTRT군에서 이명의 크기는 평균 $13.5 \pm$ $13.6 \mathrm{dBSL}$ 이었으며 최소차폐역치는 $5.8 \pm 7.9 \mathrm{dBSL}$ 이었다. $\mathrm{TM}$ 군에서 이명의 크기는 평균 $9.4 \pm 8.6 \mathrm{dBSL}$ 이었으며 최소 차폐역치는 $1.9 \pm 2.9 \mathrm{dBSL}$ 로 두 군 사이에 유의한 차이가 없 었다. 또한 치료 전 Tinnitus Handicap Inventory(THI)점수, Visual Analog Scale(VAS), 하루 중 이명인지시간에 있어서 도 두 군 사이 차이를 보이지 않았다(Table 1).

\section{청력평가와 이명의 심리음향학적 평가}

이중벽 방음실에서 GSI 10(Grason-Stadler, Inc, Madison, WI, USA) 청력검사기를 이용하여 순음청력검사를 실시하였 으며, 회화 음역에서의 기도청력역치의 산술 평균을 통해 $\mathrm{ISO}$ 기준에 따라 난청의 정도를 분류하였다. 이명의 심리음 향학적 평가는 GSI 10 청력검사기의 소리 발생 장치를 통해 재생된 순음, 협대역 잡음, 광대역 잡음, 백색 잡음을 사용하 였다. 순음의 주파수는 $250,500,750,1,000,1,500,2,000$, $3,000,4,000,6,000,8,000 \mathrm{~Hz}$ 의 10 종이었고 $1 \mathrm{~dB}$ 간격으로 0 에서 $110 \mathrm{~dB}$ 까지 소리의 크기를 조정하였다. 먼저 환자의 이명과 일치하는 소리의 주파수와 크기를 찾고, 이명이 순음 인 경우 환자의 이명과 일치하는 주파수의 협대역 잡음을 1 $\mathrm{dB}$ 씩 상승해 가며 최소차폐역치(minimum masking level, $\mathrm{MML}$ )를 구하였다. 이명 주파수가 협대역 잡음인 경우는 광 대역 잡음을 이용하여 MML를 구하였다. 잔류억제효과 $(\mathrm{re}-$ sidual inhibition, RI)는 MML+10 dB SL 크기의 소리로 60 초 동안 잡음을 들려준 후 이명의 성격 변화와 이명이 억제되 는 시간(sec)을 구하였다.

\section{음향 치료}

음향 치료용 백색 잡음은 컴퓨터를 이용하여 Gauss형 백색 잡음을 생성하였다. 음향 치료용 협대역 잡음은 Gauss형 백 색 잡음을 프로그램 필터에 통과시켜 중심 주파수를 기준으 로 중심 주파수의 0.707 배와 1.414 배인 1 옥타브의 폭을 가 진 협대역 잡음을 만든 후, normalizing 과정을 거쳤다. 협대 역 잡음의 중심 주파수는 $1,2,3,4,6,8 \mathrm{kHz}$ 였고, 이를 1 분 간 재생할 수 있는 wav 파일로 만들어 소리 카드를 통해서 출력 보정한 후 저장하였다. 각 환자별로 심리음향학적 평가 에서 나타난 이명 주파수와 일치하는 협대역 잡음과 백색 잡 
Table 1. Demographic comparison between the two groups

\begin{tabular}{lccc}
\hline & mTRT & TM & P \\
\hline No of subjects & 13 & 8 & 1.000 \\
M : F & $9: 4$ & $5: 3$ & 0.147 \\
Age & $48.0 \pm 13.0$ & $40.0 \pm 10.2$ & 0.359 \\
Rt : Lt : bilateral & $3: 7: 3$ & $4: 2: 2$ & 0.757 \\
Hearing threshold & $21.0 \pm 12.2$ & $22.4 \pm 12.0$ & 0.804 \\
Onset of tinnitus (wk) & $55.6 \pm 92.7$ & $56.6 \pm 72.4$ & 0.669 \\
PT/NB/WN & $8 / 4 / 1$ & $4 / 2 / 0$ & 0.315 \\
$250: 1 \mathrm{k}: 4 \mathrm{k}: 6 \mathrm{k}: 8 \mathrm{k}$ & $1: 1: 2: 1: 8: 0: 1: 3$ & 0.268 \\
Tinnitus intensity match (dB SL) & $13.5 \pm 13.6$ & $9.4 \pm 8.6$ & 0.210 \\
Minimal masking level (dB SL) & $5.8 \pm 7.9$ & $1.9 \pm 2.9$ & 0.210 \\
Residual inhibition (sec) & $9.2 \pm 17.8$ & $10.3 \pm 13.8$ & 0.456 \\
Pretreatment THI score & $40.0 \pm 23.1$ & $48.3 \pm 25.6$ & 0.414 \\
Pretreatment VAS annoyance & $6.1 \pm 1.3$ & $16.8 \pm 1.4$ & 0.916 \\
Pretreatment hours of tinnitus perception (hr) & $17.2 \pm 9.1$ & \\
\hline
\end{tabular}

MTRT: mixed tinnitus retraining therapy, TM: tinnitus making, PT: puretone, NB: narroe band, WN: white noise, VAS: Visual Analog Scale, THI: Tinnitus Handicap Inventory

음을 섞어서 MP3 재생장치에 입력하여 환자들에게 배포하 였다. 음향 장치의 음량 조절은 각 환자의 난청 정도에 따라 개인적으로 조절하도록 교육하였다. TM 군의 경우 자신의 이 명이 잘 들리지 않는 정도로 음량을 올리되, 이명이 들리지 않는 한 가급적 작은 음량을 사용하도록 지시하였고, mTRT 의 경우는 혼합점(mixing point)까지 음량을 조절하도록 지시 하였습니다. 즉 자신의 귀에서 들리는 이명과 음향 장치에서 발생하는 잡음이 서로 섞여서 들리는 음량으로 광대역 잡음 을 듣도록 교육하였다. 음향 치료는 매일 1 시간 이상 시행하 도록 교육하였다. 각 내원 시점마다 음향 치료를 적절하게 시 행하고 있는지 확인하여 치료에 대한 순응도를 점검하였다.

추적관찰은 치료 시작 이후 1 달 간격으로 시행하였다. mTRT 군은 첫 1 개월간 협대역 잡음과 백색 잡음의 비율을 $2: 1$ 로 구성하여 주로 협대역 잡음을 듣게끔 교육하였다. 둘째 달은 협대역 잡음과 백색 잡음의 비율을 $1: 2$ 로 바꾸어 백색 잡음 의 비율을 증가시켰으며, 셋째 달부터는 백색 잡음만 듣도록 교육하였다. 한편 TM 환자군은 처음부터 끝까지 환자가 느끼 는 이명 주파수와 동일한 협대역 잡음을 듣도록 교육하였다.

MP3 재생장치는 Sansa shaker(Sandisk, Milpitas, CA, USA)를 사용하였다. 본 장비를 선택한 이유는 가격이 저렴 하고, 조작이 쉬우며, 충전식이 아닌 누구나 쉽게 사용할 수 있 는 $\mathrm{AAA}$ 건전지를 사용하였기 때문이다. 또 이어폰 사용에 거 부감이 있거나 수면을 취하는 경우, 이어폰 없이도 외부 스피 커를 통해 음향 치료를 시행할 수 있는 제품을 선정하였다.

\section{지도 상담}

모든 환자의 지도 상담은 1 인에 의해 시행되었으며 비교적
짧은 시간 내에 진료를 해야 하는 외래 현실을 감안하여 초기 면담은 15 분 내외로 시행하였다. 이후 추적관찰시는 5 분 정도 에 걸쳐 지도 상담을 시행하였으며, 모든 지도 상담은 Jastreboff의 이명 모델과 치료 방침에 근거하여 시행하였다. 저 자들이 시행하는 지도 상담 내용을 요약하면 아래와 같다. 1) 이명의 발생기전에 대한 설명, 2) 청력검사와 이명 심리음 향학적 평가 결과에 대한 설명, 3) 이명에 대한 의문점 및 불 안감 해소, 4) 이명재훈련 치료 과정 및 치료 목표에 대한 설 명. TM과 mTRT 두 군 사이 음향 치료 방법에는 차이가 있 었지만, 지도 상담 내용에는 차이를 두지 않았다. 지도 상담 과 더불어 약물 치료로 모든 환자들에게 alprazolam $0.5 \mathrm{mg}$ 을 자기 전에 복용하도록 처방하였으며, 두 군 사이 약물 치 료 내용에는 차이가 없었다.

\section{자기 보고형 설문지 평가}

치료 효과를 평가하기 위해 환자들은 1 개월 간격으로 병 원에 내원하여 THI, VAS, 이명인지시간에 관한 자기 보고형 설문지를 작성하였다. THI 점수는 1996년 Newman이 제시 하였던 THI 점수를 정서적 스트레스와 기능적 장애, 재앙화 생각의 각 항목으로 나누어서 총 25 개의 질문 사항에 대하 여 “아니다", "가끔 그렇다", “그렇다”로 표기하도록 구성되었 으며, "아니다"는 0점, "가끔 그렇다"는 2점, "그렇다"는 4점으 로 점수를 매겨 총점을 구하였다. ${ }^{6,7)} \mathrm{VAS}$ 는 1 부터 10 까지 일 정한 간격으로 숫자가 쓰여진 줄 위에 환자가 느끼는 괴로움 의 정도를 위치로 표시하도록 하였다. 이명인지시간 하루 24 시간 중 환자가 이명을 인지하는 기간을 시간 단위로 적도록 하였다. 
모든 설문검사는 피검자가 직접 읽고 작성하는 방법을 이용 하였으나 환자가 검사를 이해하지 못하거나 스스로 작성이 불 가능한 경우에는 검사자가 읽어주고 기록하는 방법을 병행하 여 사용하였다. 의료진과 상담한 내용이 치료 결과에 영향을 주지 않도록 하기 위해 매 진료시 의사를 만나기 전에 설문을 먼저 작성하도록 하였다. THI, VAS, 이명인지시간은 치료 시작 전후로 동일한 방법으로 확인하였으며, 치료 전 점수에 비해 호전된 정도를 치료 결과로 평가하였다.

통계 처리는 SPSS v 12.0을 이용하여 Wilcoxon Signed Ranks test를 통해 분석하였다. 유의 수준이 0.05 보다 작은 경 우 유의한 차이로 해석하였다.

\section{결 과}

\section{mTRT의 단기 치료 효과}

mTRT 전후의 THI 점수를 비교한 결과, 치료 전에는 41.8 \pm 24.3 점이었고, $1 \sim 4$ 주 동안 mTRT를 시행한 후 $34.9 \pm 23.8$ 점으로 감소하였으며, 5 주 이상 시행한 후에는 27.3 \pm 25.6 점 으로 유의하게 $\mathrm{THI}$ 점수가 감소하였다 $(p<0.01) . \mathrm{mTRT}$ 전 후의 VAS 점수를 비교해 보았을 때도 치료 전 평균 $5.9 \pm 1.4$ 점이었던 것이 $1 \sim 4$ 주 동안 치료 후에는 $5.4 \pm 1.5$ 점으로 감소
하였고, 5 주 이상 치료 후에는 4.7 \pm 1.8 점으로 유의하게 VAS 점수가 감소하였다 $(p=0.01)$. 이명인지시간은 $\mathrm{mTRT}$ 전에는 평균 $18.5 \pm 8.2$ 시간이었으며, 1 4주 동안 치료 후에는 $15.1 \pm$ 10.3 시간으로 감소하였고, 5 주 이상 치료 후에는 $12.6 \pm 10.7$ 시간으로 역시 유의하게 감소하였다( $p=0.02)$ (Fig. 1).

\section{TM과 mTRT 환자군 사이 치료 효과 비교}

두 환자군의 치료 전후 $\mathrm{THI}$ 점수를 비교한 결과 $\mathrm{TM}$ 과 $\mathrm{mTRT}$ 사이 유의한 차이가 없었다. 또한 VAS 점수와 이명인 지시간도 TM과 mTRT 사이에 유의한 차이가 없었다(Table 2) (Fig. 2).

\section{고 찰}

이명재훈련은 Jastreboff ${ }^{8}$ 에 의해 소개되었으며, 현재까지 도 활발하게 사용되고 있는 이명 치료 방법이다. 이명재훈련 은 지도 상담과 음향 치료로 구성된다. 지도 상담은 청각 기관 의 기본적인 구조와 이명의 기전에 대해 Jastreboff 모델을 이 용하여 자세하게 설명하며, 이 과정을 통해서 이명에 대한 불 필요한 공포를 없애고 이명에 적응을 할 수 있는 동기를 부여 한다. 이명에 대하여 자율 신경계와 감정의 반응을 긍정적으
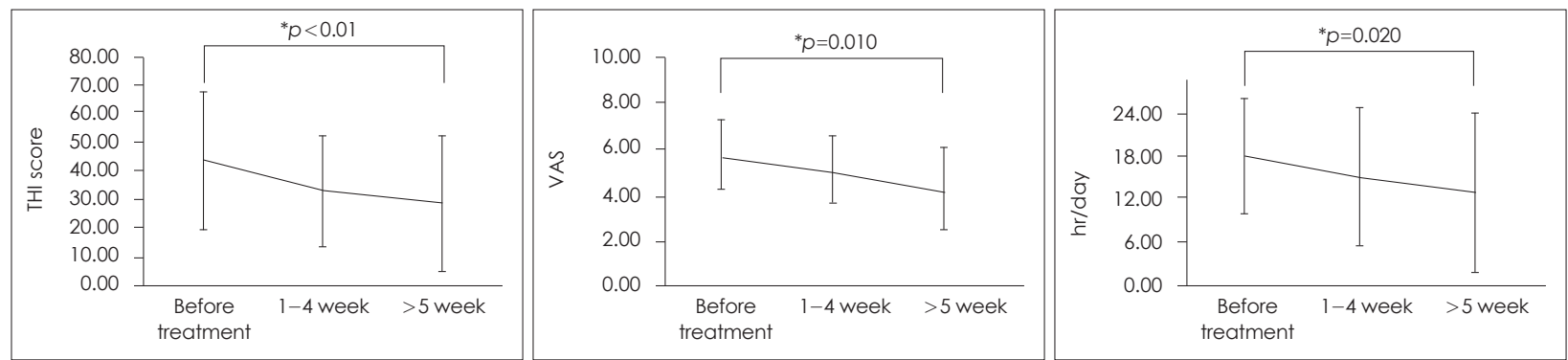

Fig. 1. Improvement in THI, VAS and tinnitus awareness duration after mixed tinnitus retraining therapy (mTRT). The THI score decreases significantly from $41.8 \pm 24.3$ to $27.3 \pm 25.6$ after mTRT. The VAS (from $5.9 \pm 1.4$ to $4.7 \pm 1.8$ ) and the tinnitus awareness duration (from $18.5 \pm 8.2$ to $12.6 \pm 10.7$ ) also showed a significant improvement after the treatment. THI: Tinnitus Handicap Inventory, VAS: Visual Analog Scale.

Table 2. Comparison on short term effects between mixed tinnitus retraining therapy (mTRT) and tinnitus masking (TM)

\begin{tabular}{|c|c|c|c|c|}
\hline \multirow{2}{*}{ Instrument, time period } & \multicolumn{2}{|c|}{ TM } & \multicolumn{2}{|c|}{ MTRT } \\
\hline & Mean & SD & Mean & SD \\
\hline THI, before treatment & 48.3 & 24.3 & 40.0 & 23.2 \\
\hline THI, 3 week & 46.3 & 22.6 & 34.9 & 23.8 \\
\hline THI, 10 week & 43.8 & 31.0 & 25.9 & 25.5 \\
\hline VAS, before treatment & 6.5 & 1.6 & 6.1 & 1.3 \\
\hline VAS, 3 week & 6.1 & 1.4 & 5.4 & 1.5 \\
\hline VAS, 10 week & 5.8 & 1.8 & 4.2 & 1.8 \\
\hline Duration, before treatment & 16.8 & 8.4 & 17.2 & 9.0 \\
\hline Duration, 3 week & 15.9 & 8.8 & 15.1 & 10.3 \\
\hline Duration, 10 week & 15.1 & 10.8 & 11.8 & 11.8 \\
\hline
\end{tabular}

THI: Tinnitus Handicap Inventory, VAS: Visual Analog Scale 

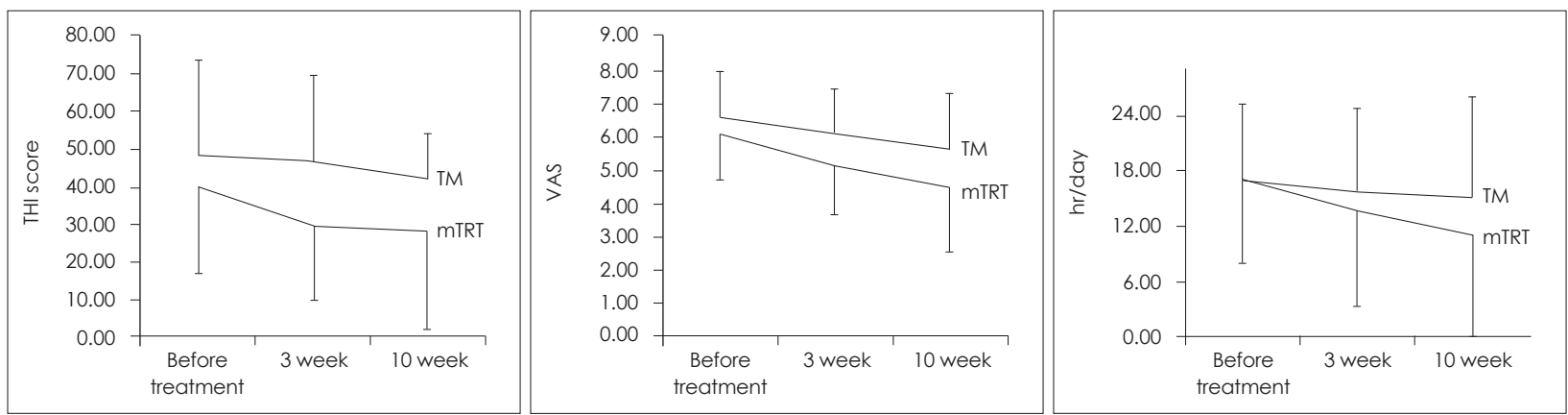

Fig. 2. Comparison on short term effects between mixed tinnitus retraining therapy (mTRT) and tinnitus masking (TM). Both treatments progressively reduced THI score, VAS, and the tinnitus awareness duration. There was no significant difference, when the treatment outcome was compared between mTRT and TM. THI: Tinnitus Handicap Inventory, VAS: Visual Analog Scale.

로 변화시켜서 궁극적으로는 변연계와 자율신경계의 습관화 를 유도하는 것이 목적이다. 음향 치료는 소리발생기(noise generator)나 보청기를 사용하여 적절한 외부 소리를 들려줌 으로써 이명의 감지 정도를 감소시키고 점차적으로 중추신 경계의 습관화를 유도하기 위하여 시행한다. $\left.{ }^{9}\right)$ TRT에서 음향 치료는 습관화를 유도하는 것이 목표이기 때문에 모든 청각 신경계를 골고루 자극할 수 있는 광대역 잡음을 사용하는 것이 일반적이다. ${ }^{4}$

반면, TM은 환자가 느끼는 이명과 비슷한 주파수의 소리를 들려주어 차폐음을 듣는 동안 즉각적으로 이명으로부터 탈 출할 수 있도록 만들어주는 것이 목적이다. Vernon ${ }^{10}$ 에 의해 이명 차폐에 대한 많은 연구가 이루어졌으며, 2003년에 발표 된 이명 차폐법의 효용성에 관한 논문에 따르면 이명 차폐를 통해 $92 \%$ 의 환자에서 완전 차폐에 성공하였으며 휴대 가능 한 장비 이용시 $70 \%$ 에서 완전 차폐가 가능하다고 보고하였 다. ${ }^{2}$ 환자에 따라 이명이 차폐되는 차폐음이 서로 다르기는 하 나 일반적으로 $\mathrm{TM}$ 은 협대역 잡음을 많이 사용한다. ${ }^{2)}$

이상과 같이 TM과 TRT는 음향 치료의 음원 특성이 매우 상반됨을 알 수 있다. 저자들이 고안한 mTRT는 치료 초기 1 2개월 동안 위 두 개념을 혼합하여 사용하였다. 따라서 서 로 목적과 특성이 전혀 다른 음원을 서로 섞어서 음향 치료를 시행하는 것이 이명의 신경생리학적인 측면에서 과연 가능한 것인지에 대한 의문이 있을 수 있다. TRT를 시행하는 경우 협 대역 잡음을 음향 치료에 사용하게 되면, 습관화를 오히려 방 해할 잠재적 가능성이 있기 때문이다. 이에 저자들은 $\mathrm{TM}$ 과 TRT를 동시에 시행하는 것이 과연 가능한 것인지, $\mathrm{mTRT}$ 의 효용성을 먼저 검증하고자 하였다. 평균 10 주 동안 추적관찰 한 결과 THI, VAS, 이명인지시간 세 가지 지표 모두 치료 기 간에 비례하여 유의하게 호전되는 것을 확인하였다. 따라서 협대역 잡음을 이용한 TM과, 광대역 잡음을 이용한 TRT를 함께 병행하여도 이명으로 인한 환자의 불편을 개선할 수 있 는 것으로 생각된다. 아쉬운 점은 치료 초기의 $\mathrm{TM}$ 이 장기 이
명 습관화에 부정적인 영향을 주는지의 여부는 본 연구를 통해 확인하지 못하였다는 것이다. 즉 추적관찰 기간이 평균 10 주로 mTRT의 장기적인 효과를 검증하지 못한 한계점이 있다. 그러나, 최소한 mTRT가 이명의 단기 치료에 효과적임 을 알 수 있었다.

다음 단계로, TM과 mTRT의 치료 성적을 비교하였다. 그 결과 두 군간에 유의한 차이가 없었으며 THI, VAS, 이명인 지시간이 비슷하게 감소하는 경향을 확인할 수 있었다. 치료 시작 후 3개월까지 TM의 치료 효과가 TRT보다 우수하다는 Henry 등의 의 논문을 참조하여, 저자들은 mTRT를 통해 기 존 TRT의 단기 치료 효과가 개선된 것이 아닌지 추정해 보았 다. 그러나 본 연구는 기존 TRT를 시행한 환자군이 별도로 설정되어 있지 않았기 때문에, mTRT와 기존 TRT의 단기 치 료 효과 차이에 대해서는 단정할 수 없을 것이다. 이러한 점도 본 연구의 중요한 한계점이며, 향후 추가 연구를 통해 이점을 명확하게 규명할 필요가 있다. 본 연구를 통해서는 다만, $\mathrm{mTRT}$ 의 치료 효과가 단기 성적이 우수한 것으로 이미 알려 진 TM과 비교하여 유의한 차이가 없다는 것까지만을 증명할 수 있었다.

한 가지 유의할 점은, 본 연구에서 시행한 지도 상담이 기존 전통적인 TRT에 비하여 매우 간결하고 짧게 이루어졌다는 점이다. 즉, mTRT가 기존 TRT와 비교하여 단지 음향 치료 방침만 변형된 것이 아니라는 지적이 있을 수 있다. 저자들도 이러한 문제점을 인정하는 바이다. 그러나 전통적인 이명재 훈련을 시행하기 위해서는 많은 시간과 인력이 필요하여 실제 임상에서 Jastreboff가 정립한 치료를 그대로 적용하기 어려 운 측면이 있다. 청각과 이명에 대해 전문적인 지식을 습득한 인력이 한 명의 이명 환자를 위해 수십 분에서 수 시간씩 시간 을 할애한다는 것은 우리나라의 의료 현실에서 매우 어렵다. 이러한 현실적인 어려움 때문에 여러 환자를 동시에 상담하 거나, ${ }^{11}$ 지도 상담을 매우 간결하고 짧게 진행하는 TRT 연구 들이 보고되고 있다. ${ }^{12)}$ 이들 보고에 따르면 지도 상담을 변형 
하여도 기존의 전통적인 TRT와 거의 유사한 효과를 얻을 수 있었다고 한다. 또 본 연구에서 비교하고자 하였던 mTRT군 과 $\mathrm{TM}$ 군은 지도 상담 내용을 동일하게 간소화하여 서로 차 이가 없었다. 따라서 비록 지도 상담이 간소화된 mTRT를 시 행하였지만, 본 연구에서 목적한 바를 규명하는 데는 큰 문 제가 없을 것으로 생각한다.

\section{REFERENCES}

1) Roberts LE, Eggermont JJ, Caspary DM, Shore SE, Melcher JR, Kaltenbach JA. Ringing ears: the neuroscience of tinnitus. J Neurosci 2010;30(45):14972-9.

2) Vernon JA, Meikle MB. Masking devices and alprazolam treatment for tinnitus. Otolaryngol Clin North Am 2003;36(2):307-20, vii.

3) Jastreboff PJ. Phantom auditory perception (tinnitus): mechanisms of generation and perception. Neurosci Res 1990;8(4):221-54.

4) Henry JA, Schechter MA, Nagler SM, Fausti SA. Comparison of tinnitus masking and tinnitus retraining therapy. J Am Acad Audiol 2002;13(10):559-81.

5) Henry JA, Schechter MA, Zaugg TL, Griest S, Jastreboff PJ, Vernon
JA, et al. Clinical trial to compare tinnitus masking and tinnitus retraining therapy. Acta Otolaryngol Suppl 2006;(556):64-9.

6) Newman CW, Sandridge SA, Jacobson GP. Psychometric adequacy of the Tinnitus Handicap Inventory (THI) for evaluating treatment outcome. J Am Acad Audiol 1998;9(2):153-60.

7) Newman CW, Jacobson GP, Spitzer JB. Development of the Tinnitus Handicap Inventory. Arch Otolaryngol Head Neck Surg 1996;122(2): 143-8.

8) Jastreboff PJ. Tinnitus retraining therapy. Br J Audiol 1999;33(1): 68-70.

9) Jastreboff PJ, Hazell JW, Graham RL. Neurophysiological model of tinnitus: dependence of the minimal masking level on treatment outcome. Hear Res 1994;80(2):216-32.

10) Vernon J. The history of masking as applied to tinnitus. J Laryngol Otol Suppl 1981;(4):76-9.

11) Henry JA, Loovis C, Montero M, Kaelin C, Anselmi KA, Coombs R, et al. Randomized clinical trial: group counseling based on tinnitus retraining therapy. J Rehabil Res Dev 2007;44(1):21-32.

12) Aazh H, Moore BC, Glasberg BR. Simplified form of tinnitus retraining therapy in adults: a retrospective study. BMC Ear Nose Throat Disord 2008;8:7. 